\title{
DISCURSOS SOBRE LA DIFERENCIA: LO MODERNO Y LO BARROCO EN LA GESTIÓN DE ORGANIZACIONES COLOMBIANAS EN LA REGIÓN DE CAUCA
}

\section{RESUMEN}

\author{
Nancy Piedad Díaz-Ortiz \\ Doutora em Administração \\ Universidad Andina Simón Bolívar \\ Quito - Equador \\ Mariana Lima Bandeira \\ Doutora em Administração \\ Universidad Andina Simón Bolívar \\ Quito - Equador \\ Universidad Estatal de Milagro \\ Milagro - Equador \\ limabandeira.mariana@gmail.com
}

El objetivo de esta investigación consistió en comprender cómo es manejada la diferencia en la gestión organizacional-entre la modernidad de la gestión y lo barroco de la dinámica social-, en un contexto cultural fuertemente influenciado por la tradición afro, desde la comprensión de los aspectos sociológicos, psicológicos e histórico-culturales; autores del pensamiento latinoamericano, como Eduardo Ibarra Colado y Bolívar Echeverría, dan visibilidad a estas contradicciones. El estudio empírico fue desarrollado en dos organizaciones de la región del Cauca, Colombia, diseñado como una etnografía enfocada, en la que participaron los dirigentes y los operarios. Se trata de una investigación cualitativa, cuyos datos fueron recolectados durante el año de 2015 por medio de la entrevista a profundidad, la observación al participante y la revisión bibliográfica-documental. El análisis fue desarrollado por medio del "Modelo de Análisis del Discurso de Greimas", que organiza las valoraciones de las personas sobre sus acciones. Como hallazgos principales encontramos que, independiente del tipo de organización, los modelos de gestión no consideran aspectos de la diferencia, gracias a su afán de unificar las subjetividades y, por ello, muchas veces los dirigentes se enfrentan a conflictos. Una contribución adicional es en relación al abordaje de la diferencia desde su construcción histórica, psicosocial y sociológica, como una práctica que deconstruye el proyecto de Modernidad de las organizaciones.

Palabras-clave: Gestión de la diversidad; "Blanquitud”; Teoría de la identidad social; Modernidad barroca.

\section{DISCOURSES ABOUT DIVERSITY: THE MODERN AND THE BAROQUE VIEW IN THE MANAGEMENT OF COLOMBIAN ORGANIZATIONS OF CAUCA REGION}

\begin{abstract}
This research aims at enhancing how diversity is handled in organizational management in a cultural context strongly influenced by the Afro tradition, since the understanding of sociological, psychological and historical-cultural aspects. Authors of Latin American thought, such as Eduardo Ibarra Colado and Bolívar Echeverría, highlight the contradictions between the Modernity (management) and the baroque characteristics of social dynamics. The empirical study was developed in two organizations in the region of Cauca, Colombia, designed as a focused ethnography, in which there were two different groups: managers and workers. Hence, It is a qualitative study, whose data were collected through an in-depth interview, along the year of 2015, with a participant observation technique and the bibliographic and documentary review. The data analysis was developed through the discourse analysis by Greimas, who proposed a series of narrative states, which structures people's valuation to their actions. We mainly found that, regardless of the organization scope, management models usually do not consider aspects of diversity in their search for unification of subjectivities; that was one of the reasons managers often face conflicts. A methodological contribution of this paper is to investigate the diversity from its historical, psychosocial and sociological construction as a practice that deconstructs the Modernity project of organizations.
\end{abstract}

Key-words: Diversity management; "Whiteness"; Social identity theory; Baroque modernity. 


\section{INTRODUCCIÓN}

Las organizaciones empresariales como cualquier organización humana está conformada por personas. La mención de esta premisa en el ámbito de la gestión, parecería redundante. Sin embargo, ésta sentencia toma sentido, dada la importancia que ha suscitado en el ámbito académico y profesional, la creación y utilización de las herramientas de gestión para aumentar la eficiencia y la eficacia organizacional. Asimismo pone, en el centro de la discusión, al hombre como protagonista de la gestión y no como un elemento que funciona a pesar de ella. El profesor Ibarra Colado advierte que "la historia de la teoría de la organización es la historia del capitalismo" (Ibarra-Colado, 2003 p. 33), dando cuenta de la racionalidad instrumental dominante en la teoría administrativa y, por esa vía, la predominancia del individuo como medio para alcanzar fines. Esta lógica contradice la visión humanizada del individuo en la gestión, como se puede percibir.

En este marco, el objetivo de este trabajo fue comprender la diferencia como una variable de la gestión, enmarcando el estudio empírico en dos empresas ubicadas en una región al norte de Colombia que se caracterizan por su contexto intercultural de raíces africanas. Una contribución transversal de este estudio, precisamente consiste en cuestionar la forma homogénea como la diferencia es tratada en los modelos de gestión de diversidad en las organizaciones, por lo que se convierte en una variable de control de la gestión. El modelo de gestión de la diversidad buscaría, en este marco, controlar la diferencia y homogeneizarla.

Su concepción, desde diferentes criterios, atraviesa las herramientas y decisiones que se toman en nombre de los diferentes actores, sin importar el orden jerárquico que ocupan en la organización. Su implementación ayuda a afianzar el discurso funcionalista institucionalizado en las empresas, en la medida en que se considera dentro de un grupo o fuera de él, al individuo que piensa y se comporta en coherencia con la lógica productiva de la eficiencia y la eficacia organizacional capitalista. A lo que se denomina endogrupo y exogrupo en la Teoría de la Identidad Social (Turner, 1982; Tajfel, 1984, Scandroglio, LópezMartínez \& San José Sebastián, 2008).

La concepción de diferencia entre los actores organizacionales internos da cuenta de la relación entre la naturaleza humana y la condición humana que plantea Hannah Arendt. La autora explica que el hombre es un ser condicionado por la interacción entre los de su misma especie y por la objetividad del mundo, es decir, el contacto relacional de unos con otros, con fines instrumentales o sustanciales, lo cual fundamenta su condición humana. Así, las actividades y capacidades del individuo corresponden a la condición humana y esto constituye una dimensión disímil de su naturaleza humana, "cualquier cosa que toca o entra en contacto con la vida humana, asume de inmediato el carácter de condición de la existencia humana" (Arendt, 1996 p. 23).

La diferencia, se puede establecer por varias causas como: la región de donde proviene el individuo, la forma en la que invierte su salario, la forma de celebrar acontecimientos sociales, el conocimiento formal y la experiencia que posee, el nivel jerárquico dentro de la empresa, la actitud preestablecida por la dinámica industrial frente al trabajo en la organización, entre otros. La diferencia atraviesa los actores organizacionales internos, permitiendo el distanciamiento necesario entre unos y otros para tomar decisiones que tienen injerencia en los individuos que se consideran como no iguales. La concepción de diferencia fortalece el discurso de la productividad y la eficiencia organizacional, siendo el marco común por el cual surge en el contexto de la empresa el cumplimiento o no de las expectativas productivas y económicas.

Bajo estos planteamientos, el objetivo de esta investigación fue comprender la diferencia en los discursos de gestión organizacional, desde tres ejes: psicológico-social, sociológico e histórico. Es importante destacar que el aporte de este texto también está en traer autores del pensamiento latinoamericano para esta discusión, como Ibarra Colado y Bolívar Echeverría.

El trabajo de campo se realizó en Colombia, en el Norte del Departamento del Cauca, una región con un alto contraste étnico, en la que confluyen afrodescendientes, indígenas y mestizos. Esta región se ha caracterizado tradicionalmente por su vocación agrícola, principalmente alrededor de la caña de azúcar y frutas. Sin embargo, la sanción de la ley 218 o Ley Páez ${ }^{1}$, que tenía como objetivo reactivar la zona afectada por la avalancha del río Páez, cambió el panorama económico-productivo de la región. En la zona se ha desarrollado el conglomerado industrial del Norte del Cauca, que dan lugar a una serie de contrastes sociales, culturales y económicos, que se mezclan y expresan en las organizaciones empresariales que operan ahí.

Se buscó un acercamiento a la realidad con un estudio de etnografía enfocada. Fueron recolectados datos por medio de observación participativa, entrevistas a profundidad y revisión bibliográfica y 
documental. Los datos fueron analizados bajo el modelo de análisis del discurso de Greimas (1973; 1976), que se sitúa en la corriente menos preocupada por lo lingüístico y más próxima a aspectos sociológicos. Como escenarios de análisis, se abordaron dos organizaciones: una empresa industrial manufacturera aquí denominada Gráficos S.A y una fundación con ánimo social llamada Fundación Cauca, creada en Puerto Tejada para atender la zona de influencia de la Planta Dos de una empresa a que denominamos Cartón.

Este texto está compuesto de cuatro secciones además de esta introducción; la sección 2 organiza la discusión teórica para comprender la diferencia desde lo psicosocial, el tabú y la perspectiva cultural e histórica; la tercera sección está dirigida a detallar la metodología del estudio, describiendo la recolección de datos y el análisis realizado. En el acápite siguiente se presentan los resultados en tres momentos: el contexto de las organizaciones, los resultados, el análisis y una síntesis. Por último, la quinta sección está dirigida a tejer algunas consideraciones finales.

\section{EJES TEÓRICOS PARA LA COMPRENSIÓN DE LA DIFERENCIA}

Haciendo un análisis retrospectivo de donde proviene la diferencia en el contexto de América Latina de habla hispana, se encuentra un factor histórico y espacio-temporal específico: la colonización española en los territorios y pueblos nativos latinoamericanos ${ }^{2}$. La idea de diferencia, claro está, no nace en el encuentro de los europeos con los indígenas latinoamericanos, pues esa concepción ya está predefinida en los individuos que arribaron a estas tierras; sino en el tabú como un elemento sociológico antiquísimo que propone el primer establecimiento de la diferencia entre los seres tabuados y los no tabuados (Frazer, 1969), dando lugar a su vez a la psicología de la diferencia y por tanto a la expresión lingüística y simbólica de la diferencia. Estas dos dimensiones se combinan y se complementan para una comprensión más compleja de la diferencia entre los actores organizacionales internos.

Por lo tanto, la concepción de diferencia entre unos y otros individuos, y por ende entre unos y otros grupos sociales (capitalistas-empleados) en las organizaciones, tiene antecedentes psicosociales, sociológicos e histórico-culturales, pues lo que pasa en las organizaciones es una representación de las relaciones del hombre con su otro igual en cualquier ámbito, acentuada en forma particular por variables e intereses de índole económico.

\subsection{La diferencia desde la dimensión psicosocial en las organizaciones}

En el contexto de la administración como ciencia social aplicada y su estudio de la relación del hombre con otros semejantes en el ámbito de las organizaciones, el llamado de la corriente del humanismo administrativo por "humanizar" la administración parecería una doble contradicción en el contexto de la modernidad. Esta corriente filosófica busca la liberación del hombre a través de la razón. Sin embargo a las contradicciones observadas en la relación del trabajador con las organizaciones, en los albores de las primeras décadas del siglo XXI, este llamado de liberar al hombre de las cadenas que lo atan está más vigente que nunca.

Entre estas contradicciones, está llamar a la organización de un proyecto humano: La organización ¿no es acaso un grupo de individuos, seres humanos que buscan objetivos comunes? La respuesta a la pregunta quizás se pueda encontrar en la naturaleza y la condición humana de la que habla Arendt (1996): se puede evidenciar esta diferenciación en las organizaciones cuando se establecen roles, ya que, de esta manera, el individuo simplifica su naturaleza humana para que tome forma su condición. Esto es, el ser humano enmarcado dentro de unas reglas, interpretando un papel que está predefinido por los grupos sociales, por la historia y por la cultura, convirtiéndose en un actor enmarcado en un contexto socialmente definido.

Así, la apropiación de estos roles, de alguna manera facilita y canaliza el comportamiento y los resultados que se espera de ellos; un claro ejemplo se puede analizar en el rol que asume el hombre en la guerra, "es preferible dirigirse a los combatientes como guerreros antes que como seres humanos, ya que los guerreros, respetan códigos de honor y los seres humanos-en calidad de tales-carecen de los mismos" (Ignatieff, 1998 p. 15), de esta forma cuando el individuo asume un rol, se convierte en un ser humano recortado en su esencia.

Ignatieff (1998), en su recorrido por los países de medio oriente y África que sufren conflictos étnicos, plantea importantes aportes acerca de la diferencia, derivados de su contacto con los guerreros de una y otra parte. Da a conocer que, en principio, a los ojos de cualquier persona ajena al conflicto, las partes en guerra no son susceptibles de diferencia alguna; no obstante, entre sus relatos se aprecia la respuesta de un 
Discursos sobre la diferencia: lo moderno y lo barroco em la gestión de organizaciones colombianas

soldado serbio respecto a los croatas, a quien se le había preguntado: ¿por qué se creen tan distintos? El soldado serbio argumentaba desprevenidamente que no tienen nada en común, posteriormente planteaba que los croatas se creen mejores y finalmente admitía que todos "somos los mismos". Al fin y al cabo el rol del soldado es atacar y, en el mejor de los casos, defender un ideal.

Seguramente la última respuesta del soldado proviene de su análisis desde la naturaleza humana que comparten; lo que los diferencia, entonces, no es su esencia, sino su relación de acercamiento con unos y de distanciamiento con otros, un rasgo cultural o ideológico que, en este caso particular, se trata del nacionalismo que define su identidad, no desde lo que es, sino desde lo que no es, tomando fuerza la unidad de los contrarios en el contexto particular de la guerra étnica de medio oriente, por tanto, ¿qué es un Serbio? Es él que no es Croata.

En el plano del establecimiento de las diferencias, es necesario identificar por lo menos dos grupos: Yo y los que son semejantes a mí, y el Otro o los Otros, del cual se quiere agrandar la distancia, por cuanto existe "la tensión entre el "nosotros" y el "ellos", la diferencia que marca la frontera entre los unos y los otros, la identidad que deriva de esa diferencia y la amenaza que para los unos y los otros representan dicha diferencia" (Cruz Kronfly, 2003 p. 163).

Freud (1917), en el Tabú de la Virginidad, propone que las pequeñas diferencias son las que producen sentimientos de hostilidad, algo así como un continuo entre estos dos elementos de una misma recta, una analogía que liga los dos conceptos. De tal manera, se evidencia diferencia en el otro y en consecuencia hay hostilidad entre las partes: es el narcisismo de las pequeñas diferencias el que agranda la distancia entre unos y otros.

Estos conceptos son discutidos por autores como Tajfel (1984), Brewer \& Weber (1994) y Turner (1982), que aportan de forma significativa a la Teoría de la Identidad Social (TIS). El planteamiento central, busca describir la dinámica de identificación con un grupo social en particular y alinea su proceder en función de la pertenencia a dicho grupo, dando lugar a la identificación del endogrupo y el exogrupo, este último hace referencia al grupo de individuos que representan otra forma de pensar y por tanto de actuar. El proceso es descrito sobre la base de tres componentes: el cognitivo, el evaluativo (positiva o negativamente) y el emocional (el vínculo afectivo que establece compromisos) (Ellemers, Kortekass \& Ouwerker, 1999). Estas contribuciones explican la concepción de diferencia de los grupos internos organizacionales, a partir de la identificación o distancia de un individuo frente a otro u otros en el contexto organizacional, y a partir de ahí, la adopción de ciertas normas implícitas y explícitas de comportamiento que forman un grupo cohesionado y hacen visibles las divisiones.

La actitud positiva hacia los miembros del propio grupo, producida de esta forma es denominada atracción social, y define un modo de atracción en el cual los sujetos no son apreciados en tanto que son individuos únicos, sino en las encarnaciones del prototipo grupal, existiendo una mayor atracción en la medida en que son percibidos como más prototípicos (Scandroglio et. al, 2008).

\subsection{El tabú, los tabuados y los no tabuados en la perspectiva sociológica de las organizaciones}

Retomando la idea de rastrear la concepción de diferencia que lleva predefinido el individuo a la organización, es necesario, desde la perspectiva sociológica, vincular al tabú como una concepción "que abarca todos los acontecimientos y casi todos los actos de la vida, constituyendo factores sugestivos, de primer orden, que ejercen una influencia perdurable y crean un estado de ánimo especial" (Castiglioni, 1972 p.101).

En palabras de Wundt (1907), precursor de la psicología experimental, el tabú es considerado como el más antiguo de los códigos no escritos de la humanidad, anterior a todos los dioses y las religiones. De esta forma, Aktouf (2003 p. 70) cobra sentido, cuando expresa: "la angustia existencial a la que el hombre siempre ha tratado de encontrar solución y lo ha hecho, de la manera más apropiada a su naturaleza de ser imaginador: mágico-místico, metafísico o fantasmático". El autor analiza los textos de Shakespeare en los que claramente se nota una doble connotación sobre el rey Enrique V o Ricardo II, donde se cruzan y se confunden lo humano y lo divino, tratando de encontrar en la literatura los argumentos para explicar los diferentes calificativos de divinidades que los empleados indirectamente le dan a los dirigentes de las organizaciones, asociándolos con veleidades, faraones o dioses, incluso de personas que se creen descendientes de extraterrestre o con poderes sobre-naturales.

Jay (2009 p. 153) rescata el concepto del tabú como "una prohibición o inhibición resultante de la costumbre social o de una aversión". Sin embargo, también el tabú está identificado como una palabra polinesia que encierra dos significados opuestos: "la de lo sagrado o consagrado y la de lo inquietante, 
peligroso, prohibido o impuro. [...] el concepto de tabú entraña, pues, una idea de reserva y, en efecto, el tabú se manifiesta esencialmente en prohibiciones y restricciones" (Freud, 1982 p. 29).

Desde el ámbito latinoamericano, Castiglioni (1972 p. 101) afirma: "El tabú consiste en un infinito número de limitaciones y prohibiciones, que pueden multiplicarse ilimitadamente, sin explicación o justificación". Esta perspectiva entiende que no existe comunidad de individuos en toda la historia de la humanidad en la que no se encuentren rastros de tabú, en forma de reglas para lo prohibido o lo protegido. En concordancia, las empresas, como una forma de organización, no se escapan de esta circunstancia, aun estando enmarcadas en el contexto de la modernidad. Acercando la concepción del tabú en el ámbito organizacional, se podría afirmar que es el conjunto de preconcepciones que demarcan y limitan las relaciones entre los actores organizacionales internos, y que dan lugar al origen de la diferencia entre unos y otros; como preconcepciones heredadas por otros individuos con los que hay algún tipo de identificación social. De esta forma, el tabú permite hilar/conectar y transmitir la dimensión del individuo, con el funcionamiento de los grupos y coherentemente con las regulaciones sociales.

Frazer (1969) clasifica el tabú en actos, personas, objetos y palabras tabuadas, lo que marca significativamente la diferencia entre una persona tabuada y otra no tabuada, dado que esta última no es objeto de prevención alguna por parte del grupo social que la rodea. En estos términos, el concepto de tabú puede explicar que el origen de la diferencia entre capitalistas y empleados o dirigentes y dirigidos va más allá de la concepción económica, porque lo que realmente importa no es la diferencia, sino lo que ésta representa frente a otros, la forma como se expresa en relación con los demás individuos.

Como lo menciona Jay (2009), la interiorización del tabú es individual. Sin embargo, las condiciones para la construcción del tabú son sociales. En el caso concreto de la palabra tabú, se aprende a utilizar en los contextos sociales en correspondencia con las personas que estén cerca y las situaciones que se presenten. De hecho, el autor expone que los niños que empiezan a hablar no tienen conciencia acerca de las palabras consideradas tabú. Éstas adquieren significado y sentido a través de las prácticas del habla y de la vida cotidiana. Este planteamiento sostiene la perspectiva social del tabú, pues las personas no nacen tabuadas, el contexto específico y las relaciones jerárquicas entre individuos son los que le dan esta forma:

En el nivel institucional, los tabúes sobre ciertas formas de discurso provienen de las autoridades que tienen el poder de regular el discurso y pueden actuar como árbitros de los discursos que hacen daño - buenos ejemplos son los tribunales de justicia, los líderes religiosos, los educadores y directivos de medios de comunicación. Las autoridades que definen el discurso del tabú (lo que es y lo que no es tabú) ejercen su poder por medio de la vigilancia y del castigo a quienes violen la prohibición. (Jay, 2009 p.153) ${ }^{3}$

Así lo constató Ignatief (1998) en su investigación en medio oriente, en el contexto de las guerras étnicas: "ninguna diferencia importa demasiado hasta que se convierte en privilegio, en el fundamento que justifica la opresión. El poder es el vector que agranda lo pequeño" (Ignatieff, 1998 p. 53); es decir, el tratamiento diferenciado entre unos y otros se da en el espacio social.

En el contexto del desarrollo de la modernidad, el tabú fue "superado" por la razón, por ser asociado con la época primitiva del hombre y, de la misma manera, se suprimieron las bases de explicación de la relación del hombre con su semejante y con la naturaleza, a través de la existencia de seres supraterrestres que premiaban y castigaban al hombre, según sus acciones. Posteriormente, ligado a concepciones religiosas y morales, el tabú, como lo manifiesta Freud (1982), transciende de la relación con la autoridad, tomando vida propia, y siendo argumentado, sostenido y reproducido por elementos socio-culturales históricos, psicológicos y antropológicos, que dan lugar a las preconcepciones en las organizaciones. En relación con los actores organizacionales internos, estos elementos constituyen un lenguaje abstracto, traducido en forma de símbolos, palabras, actos, señales y otros tantos, que son aprendidos en la cotidianidad del espacio organizacional y que traspasan el contacto físico, al acercarse con algo relacionado con la persona objeto de tabú.

Al igual que el tabú de las cosas, en las personas dicha preconcepción que demarca y limita las relaciones entre unos y otros, generalmente se las entiende mediadas por las relaciones de poder; en el caso de las organizaciones, se trata del poder de una autoridad (el dueño del capital o dirigente) sobre el que vende su mano de obra como mercancía en el contexto del capitalismo o sobre el dirigido. Pero el tabú va más allá de virtudes, poderes o encarnaciones de deidades ejercidas por las personas. Son las mismas personas las que emanan ciertos imaginarios que son expresados en forma de símbolos, y capaces de construir y consolidar los tabúes en el medio organizacional. 
Freud (1982) clasifica como el tabú natural o directo y el tabú transmitido o indirecto. El tejido de signos y símbolos en forma de comunicación, que es ejercida por los dirigentes y entendida por los dirigidos, se podría constituir como un tabú directo, encaminado hacia la protección de los capitalistas, dada la masiva demanda de los trabajadores, por lo que parecería un tabú o una regla racional, lo que se podría considerar como una abstención en el contacto de un individuo con otro, que no se configura como un ceremonial: "La noción de tabú de Wundt comprende todos los usos en los que se manifiesta el temor inspirado por determinados objetos relacionados con las representaciones del culto y por los actos relacionados con ellos alcanzados" (Freud, 1982 p.15).

\subsection{La diferencia desde la perspectiva histórico-cultural}

La modernidad en el contexto latinoamericano presenta variables diferenciadoras en relación a su lugar de origen, pues las características espacio-temporales en las que surge el proyecto de la modernidad se presentan en el denominado viejo continente en el siglo XVI, lo cual marca un punto de referencia importante. Ha terminado de transcurrir la Edad Media, caracterizada por el oscurantismo intelectual en el que el conocimiento aún parcializado, era reservado para determinadas clases sociales, con la consecuente secularización por parte de la religión, como una de las principales instituciones de la época, de cualquier rasgo de conocimiento empírico, que fue tomando otra dimensión a través del arte (Quijano, 2000).

Es posible que la cultura europea a través de los conquistadores, haya introducido consigo en el territorio americano un espacio y tiempo discordantes con la realidad de los nativos de los territorios conquistados y con esto la modernización como un proceso histórico que se ve reflejado en el desarrollo de la técnica para facilitar el trabajo del hombre, como el surtimiento de procesos productivos más eficientes, pero que no necesariamente se desarrolla paralelamente con la modernidad en su dimensión de proyecto cultural.

Por otra parte, las particularidades que se suscitaron en el encuentro generado entre europeos, africanos e indígenas por cuenta de la colonización europea y española concretamente, forja un nuevo orden en territorio indígena, enmarcado por la concepción moderna de los colonos respecto a los pobladores nativos y a los africanos: "cuando los españoles encontraron a los nativos amerindios, estos fueron clasificados inicialmente como gente bárbara, es decir, gente no civilizada, sin ciudades, sin organización política y sin uso de la razón" (Wade, 2004 p. 4). La concepción de los ibéricos con relación a los africanos era de menor consideración que los indígenas, puesto que "África era ya conocida como una región no sólo de bárbaros, sino sobre todo de infieles" (Wade, 2004 p.6). Es preciso reconocer que en el contexto contemporáneo, esta consideración de dignidad menor de los grupos indígenas y de los afrodescendientes persiste, ya no entre los colonizadores españoles, sino entre la generación de mestizos sobrevivientes.

Esa lucha de culturas divergentes, una por dominar (la europea) y la otra por perpetuarse (indígena y africana), da lugar a lo que es hoy el individuo andino y el latinoamericano en general, una expresión amorfa de ancestros indígenas y africanos enmascarados de rasgos europeos, en el sentido estricto de la expresión cultural, como intento de reconstruir la identidad no reconocida por los colonizadores y por los propios, y que estuvo obligada a auto negarse como estrategia de supervivencia, a la luz de la imposición del poder.

Entendiendo lo anterior, este proceso de colonización contempla dos frentes para preservar la identidad europea-española: por un lado, la instauración de la diferencia, ratificando al otro como un individuo de menor categoría porque no se parece, no se comporta, pero fundamentalmente porque no piensa como la masa identitaria considerada de "mejor" categoría; y por otro, de forma complementaria, el de convertir a ese diferente como uno más del que se quiere que sea, para lo cual se debe reescribir su cultura, proceso al que Bolívar Echeverría llama blanquitud:

La condición de blancura para la identidad moderna pasó a convertirse en una condición de blanquitud, esto es, permitió que su orden étnico se subordinara al orden identitario que le impuso la modernidad capitalista cuando la incluyó como elemento del nuevo tipo de humanidad promovido por ella. Es esta la razón de que, en principio, en la modernidad capitalista, los individuos de color puedan obtener la identidad moderna sin tener que "blanquearse" completamente; de que les baste con demostrar su blanquitud. (Echeverría, 2010 p. 61)

En el caso concreto del departamento del Cauca, espacio en el que se realizó el trabajo experimental de esta investigación, vemos cómo su capital, la ciudad de Popayán, que otrora correspondía al centro 
político y social más importante de La Gran Colombia, es reconocida hoy por su denominación como La Ciudad Blanca de Colombia gracias fundamentalmente a su particular arquitectura colonial, caracterizada por sus paredes blancas, pero además es una ciudad donde los rastros de la identificación por apellidos prevalece (Castrillón, Chaux, Simmonds, entre otros). Esto ocurre pese a que el Cauca alberga el 10\% de la población del territorio nacional, siendo que el 27,2\% de esta población departamental es afrodescendiente, lo que implica afirmar que concentra un cuarto de todos los afrodescendientes del país (CEPAL, 2009). Este cuadro indica que es posible afirmar que su ciudad principal guarda arraigadas costumbres de discriminación étnica, tanto hacia las comunidades indígenas como hacia la población afrodescendiente de la costa pacífica, separada del centro regional por la selva que la antecede desde las montañas y con la cual no hay comunicación por vía terrestre.

Encontramos, entonces, que la idea de blanquitud en la sociedad capitalista moderna, traída a la América indígena por los conquistadores, proviene del protestantismo ascético que propone Weber (2006) en la ética protestante y el espíritu del capitalismo, donde identifica la esencia del calvinismo, esto es el llamado de Dios que "exige a los suyos no 'buenas obras' sino una 'vida santa' es decir una santificación por las obras elevadas a sistema" (Weber, 2006 p. 32). De esta manera, Weber concluye que es el modo de vida que se espera de los seguidores de este grupo religioso, lo que propicia la acumulación de riqueza.

De esta forma, la blanquitud que se promueve no es tanto étnica como de comportamiento de los individuos: se trata de un hecho que hizo que la apariencia blanca de esas poblaciones se asimila a esa visibilidad indispensable de la santidad capitalista del ser humano moderno, y se confundiría con ella. La productividad como síntoma de la santidad moderna y como manifestación del destino profundo de la afirmación nacional pasó a incluir, como acompañante indispensable, a la blancura racial cultural de las masas trabajadoras (Echeverría, 2010 p. 60).

La concepción de blanquitud, por lo tanto, responde a los dos frentes de negación del individuo: por un lado, la falta de reconocimiento del otro como un mundo no explorado pero que sin embargo es válido, que en el contexto de la conquista no se toma en cuenta, pues no se reconoce la naturaleza humana en los pobladores indígenas. Por otro lado, está la necesidad de hacer del otro un lienzo en blanco sobre el cual reescribir una forma de pensar y comportarse que sea parecida a la que se quiere imponer, dando lugar a los orígenes de una concepción eurocéntrica del saber y del ser. Aun así, es preciso decir que dichas formas impuestas fueron de cierta forma adoptadas y re-significadas por los indígenas del siglo XVII y XVIII, como una manera de sobrevivir a la devastación de su ser, lo que Echeverría (2008) denomina el ethos barroco.

Con todo, vemos que una de las tantas consecuencias de la concepción de diferencia entre conquistados y conquistadores dio origen también a la desigualdad en cuanto a las condiciones laborales entre unos y otros, pues los europeos estaban destinados a ocupar altos cargos jerárquicos, cercanos a la realeza, mientras los indígenas estaban asignados a trabajos forzados, desde su primera concepción de esclavos y posteriormente como servidumbre libre, pero además no pagados por considerarse inferiores:

La clasificación racial de la población y la temprana asociación de las nuevas identidades raciales de los colonizados con las formas de control no pagado, no asalariado, del trabajo, desarrolló entre los europeos o blancos la específica percepción de que el trabajo pagado era privilegio de los blancos. La inferioridad racial de los colonizados implicaba que no eran dignos del pago de salario. Estaban naturalmente obligados a trabajar en beneficio de sus amos. (Quijano, 2000 p. 207)

De forma particular, este precedente tiene una fuerte influencia en las relaciones laborales contemporáneas, como lo plantean Calderón, Hopenhayn \& Ottone (1996 p. 46): "la negación no se interrumpe: se transmuta...el estigma no se interrumpe ni con las revoluciones de independencia, ni con las empresas modernizadoras, ni con el estado de derecho". En este orden de ideas, la forma como se comportan los actores organizacionales internos, de sumisión y de autoridad, tiene sus orígenes en este aspecto histórico-cultural. Existen artefactos legales, como de los derechos humanos, que de alguna manera han reducido ese comportamiento, pero aún es común en el medio laboral observar agresiones, acosos psicológicos o sexuales, discriminación por sexo, de forma explícita o simbólica.

\section{CONSIDERACIONES METODOLÓGICAS}

Para el objetivo de la investigación, de comprender cómo la diferencia es tratada en la gestión organizacional, partiendo de la realidad dos empresas colombianas ubicadas en contextos particularmente 
Discursos sobre la diferencia: lo moderno y lo barroco em la gestión de organizaciones colombianas

singulares, el enfoque cualitativo toma sentido en la medida en que "el interés de la investigación cualitativa es entender una situación social particular, un evento, rol, grupo o interacción" (Locke, Spirduso \& Silverman, 1987 p. 39). Además, permite que el investigador gradualmente obtenga "el sentido de un fenómeno social por contraste, comparación, replicación, catalogación, y clasificación del objeto de estudio" (Miles \& Huberman, 1984 p. 22).

El estudio empírico se justifica entonces en el marco de este enfoque cualitativo con elementos etnográficos, utilizando como técnicas la entrevista a profundidad, la observación participante y la revisión bibliográfica y documental.

Para el estudio de campo, que se llevó a cabo en el 2015, se utilizaron principalmente la observación y las entrevistas a profundidad, las cuales permiten una descripción ampliada, no solamente del grupo social, sino también del contexto en el que ordinariamente se desenvuelve e influencia a la comunidad, y que dirige la forma de pensar y de actuar de los individuos.

Inicialmente hubo un acercamiento con algunos actores gremiales de la zona, con el objetivo de indagar concretamente acerca de iniciativas puntuales como la implementación del programa Región Socialmente Responsable del Pacto Global, en el Norte del Cauca e iniciativas particulares de las empresas, objeto de este estudio. Esta indagación buscó establecer vínculos puntuales con los dirigentes organizacionales, y hacer la incursión en las empresas. De tal manera que fueron entrevistados: la directora y la asistente administrativa de la Asociación Nacional de Industriales, seccional Cauca —ANDI—, la directora de la Cámara de Comercio del Cauca — seccional Santander de Quilichao- y al director de competitividad, sostenibilidad y valor compartido de la zona franca del Cauca, quienes además de aportar datos que corroboraron la información de la primera etapa, permitieron establecer contactos con diferentes dirigentes organizacionales de las empresas.

Ya en las organizaciones, la observación focalizada y selectiva corresponde a una identificación de aspectos particulares significativos en cada organización, que inició con una visita exploratoria de presentación y acuerdo de las condiciones del trabajo, y además permitió el reconocimiento de los dirigentes de las áreas funcionales y el suministro de información básica; ello se analiza y contrasta con otros instrumentos de recolección de información, las posibles divergencias, coherencias y puntos de encuentro.

Para la etapa de entrevistas, de acuerdo con Spradley (1979), se utilizaron tres tipos de cuestiones: descriptivas, estructurales y de contraste, que corresponden a diferentes momentos de la investigación y que fueron acompañadas de forma paralela a las diferentes etapas de la observación. Para el conocimiento inicial, se utilizaron preguntas que básicamente buscan una descripción de las actividades más significativas de un espacio, tiempo, personas y acciones, las cuales pueden ser amplias o limitadas. Esta clase de preguntas se utilizó especialmente con los directores de las organizaciones y con las personas con que se realizó el contacto inicial, que en las dos organizaciones coincidió con ser un director de área, en el caso de Gráficos S.A el director de talento humano y en la Fundación la coordinadora de educación.

Las preguntas de experiencia o contraste, por su parte, ayudan a acercarse a las prácticas de las personas, actividades y lugares; en este caso es importante tener en cuenta la intervención o réplica por parte del investigador para indagar y especificar, formulando preguntas de ejemplos, comunes en las entrevistas etnográficas. Las preguntas de experiencias constituyen una fuente de información relevante que alimenta el objetivo planteado en esta investigación.

De otro lado, las cuestiones estructurales permiten comprobar o corroborar información derivada de etapas previas en el proceso de investigación, además ayudan a estructurar ideas de los signos que le ha proporcionado el entrevistado como conceptos, relaciones semánticas etc. Adicional a la observación y a la revisión documental y bibliográfica, específicamente de la cultura afrodescendiente, fue necesario acudir a un experto para ilustrar las características culturales de este grupo étnico, para lo cual se realizaron dos entrevistas con el Doctor en Estudios Culturales latinoamericanos, Adolfo Albán (2007), investigador en cultura afrodescendiente en el departamento del Cauca, Colombia.

Para el tratamiento de datos se utilizó el análisis del discurso de la escuela de semiótica discursiva de París, adoptando el modelo de Greimas (1973, 1976), que propone tres estados en los que transita el individuo: el virtualizado, el de hacer y la realización; estos estados revelan las valoraciones de las personas y en consecuencia las actuaciones de los mismos, analizados desde una perspectiva crítica. Las categorías utilizadas fueron delimitadas por el modelo de Greimas (1976): la categoría de manipulación, el estado virtualizado, el estado del hacer, los obstáculos, el estado de realización y la valoración. Este abordaje, además, permitió la producción de datos descriptivos, derivados del acercamiento con el campo de estudio, que poseen significados ricos y valiosos, y su objetivo fue apoyar al entendimiento de la dinámica de las relaciones sociales. 
Cada entrevista de los actores organizacionales fue identificada con la letra $\mathrm{E}$, seguido del número de la entrevista, por ejemplo, E1, E2, E3, para cada organización en particular. El siguiente paso fue identificar las macrocategorías y categorías, en cada entrevista realizada, asignándoles un color que las identificaba. Posteriormente se procedió a determinar la identificación de cada párrafo donde se localicen los hallazgos con la letra $\mathrm{P}$ y el número que corresponde. Finalmente, se agruparon los hallazgos en tablas por categoría, permitiendo identificar la recurrencia de las variables dentro de cada organización. A partir de la identificación de estos hallazgos recurrentes en cada organización y de los datos obtenidos a partir de la observación, las fotografías y la revisión documental, se procedió a realizar el análisis respectivo. En este texto, se optó por presentar los extractos de los discursos, y no la tabla.

\section{RESULTADOS}

Esta sección se construye en tres momentos. El primero se dedica a describir el contexto social específico en que se ubican las organizaciones estudiadas, considerando las bases culturales de la región. El segundo se dirige a presentar y analizar los discursos, en el marco del referencial discutido previamente y el tercer acápite fue construido como una síntesis del análisis realizado, para dar una visión global de los resultados.

\subsection{El contexto de las organizaciones estudiadas}

El contexto estudiado es marcado por una heterogeneidad de condiciones históricas, geográficas, climáticas y étnicas de estos territorios, manifestada en las organizaciones empresariales de la región. La concepción de vida de los indígenas y afrodescendientes disiente mucho de la racionalidad unilateral moderna-capitalista, por lo que recordamos que el entendimiento del contexto es importante ya que es de ahí que se deriva su racionalidad y comportamiento en el grupo organizacional.

Se conoce que la primera incursión de población afrodescendiente en la región Norte del departamento del Cauca se da en 1546, comprada como esclava en Cartagena de Indias, debido a la estrategia de reemplazar a los indígenas que se encontraban al borde del exterminio por los tratos inhumanos a los que habían sido sometidos como mano de obra por parte de los colonizadores (Castellanos, 1980). La provincia del Cauca era muy rica en oro, sin embargo faltaba fuerza de trabajo para extraerlo, por lo que los afrodescendientes fueron dedicados a trabajos forzados en las minas, la agricultura y la servidumbre. El Norte del Cauca hacía parte de la provincia de Popayán, integrada por tres cantones: Popayán, Caloto, y Almaguer.

En la categoría de esclavos, los afrodescendientes no poseían ningún derecho, vivían en las haciendas de sus amos, con no mayor recompensa por su trabajo que el techo, la comida, la ropa y el adoctrinamiento a la iglesia católica. Desde las primeras épocas de la ocupación de los afrodescendientes en la región, se trató de controlar sus expresiones culturales ancestrales, ricas en fiestas y celebraciones alrededor del baile, como lo expresa Castellanos (1980) cuando plantea que el general Mosquera, uno de los grandes terratenientes caucanos, ordenaba a los mayordomos de sus haciendas no dar permiso a bailar a los negros sino cuando hubiera un motivo especial, además nunca lo podrían hacer en la casa de la hacienda por considerar que esta actividad contradecía la moralidad y el respeto del amo. En ese sentido, Bastide (1967) resalta la importancia del baile en los afrodescendientes cuando manifiesta que los amos se dieron cuenta que si no les daban el espacio para bailar y celebrar las fiestas tradicionales, éstos morían rápidamente o disminuían su rendimiento, debido a la significancia y relación que para estos individuos tenía la festividad con la espiritualidad y la religiosidad.

Esta mezcla de factores, como la falta de educación escolarizada, incidió significativamente en el desarrollo de artes expresivas y la oralidad como medio de conservación de las costumbres ancestrales africanas. Así, la mezcla de elementos de la religiosidad africana con la iglesia católica, sumados a la opresión a la que fueron sometidos por siglos en calidad de esclavos, coexisten en los rasgos culturales de las poblaciones afrodescendientes contemporáneas (Rojas, 2004).

La población afrodescendiente del Norte del Cauca no es diferente a esta caracterización cultural, donde "La música, el canto, la danza, integrados en un complejo festivo de intensa participación colectiva, es uno de los rasgos vitales de las poblaciones de ascendencia africana" (Mosquera, Pardo \& Hoffman, 2002 p. 17).

De acuerdo con Albán (2007), la racionalidad de los afros tiene que ver con tres tiempos fundamentales en estas comunidades culturalmente diferenciadas: el tiempo de la producción, que es el 
Discursos sobre la diferencia: lo moderno y lo barroco em la gestión de organizaciones colombianas

tiempo rutinario de las labores cotidianas; el tiempo del ocio, que es el tiempo de la alegría y la felicidad y que tiene que ver con la festividad, fundamental para ellos puesto que constituye el tiempo de distención de la vida cotidiana; y por último el tiempo de la espiritualidad.

En los tiempos festivos se destacan las festividades religiosas que están inmersas en los tiempos espirituales, pues en coherencia con el eclecticismo cultural de las comunidades afros, no necesariamente se encuentran marcadas por una institucionalidad de una iglesia en particular, sino por las creencias que constituyen la espiritualidad de la gente. En estos tiempos de festividades se presentan otras lógicas de la manera como se asume el trabajo y la fiesta, también en estos espacios de celebración de las fiestas patronales se evidencian tensiones entre la iglesia y la comunidad, precisamente porque no hay una separación de lo que en términos técnicos se ha considerado lo sacro y lo profano, por tanto son celebraciones donde hay una combinación entre lo popular, considerado como mundano, y lo religioso o lo sacro.

Estas comunidades van organizando el tiempo de la vida diaria como los tiempos anuales, diferenciando una lógica distinta a la del sistema productivo permanente, porque los tiempos festivos rompen con la vida cotidiana, es allí donde se produce la distención que se considera necesaria. Así, las comunidades afro de origen campesino desarrollan una relación directa entre el tiempo que transcurre en un día, vinculado a factores como el entorno y la temperatura del día. En las comunidades asentadas en tierra cálida, como el caso del Norte del Cauca, las personas inician su jornada laboral muy temprano, entre las cinco de la mañana y la una o dos de la tarde. Las actividades que realizan los individuos en la tarde son variadas, una buena parte de ella es dedicada a actividades lúdicas, como jugar cartas, dominó o simplemente dialogar con los amigos y vecinos, esta distribución del tiempo se distancia del impuesto por el sistema productivo estandarizado por la economía industrial, y en gran parte este manejo diferenciado del tiempo y del espacio es el que ha contribuido a que se estigmatice a los afrodescendientes como perezosos.

Pero es preciso tratar de comprender más a fondo lo anterior y tener en cuenta que las comunidades africanas traídas a territorio americano se caracterizaron, justamente, por una postura contra-hegemónica, tal vez la más desatacada es el cimarronaje, entendido como la reacción a la imposición de ser esclavos, a través del abandono del sistema que oprime y la formación de pequeñas comunidades libres, alejadas de los centros colonizadores; este fenómeno se dio en toda América Latina, de forma independiente desde el siglo XVI. Vemos, entonces, que las poblaciones del Norte del Cauca vienen de procesos históricos de cimarronaje, de hecho existen indicios de que en el Norte del Cauca se ubicaron dos palenques ${ }^{4}$, precisamente en el municipio de Caloto y en el municipio de Puerto Tejada.

Es preciso reiterar, asimismo, que esta región presenta una lógica heredada del cultivo de la caña de azúcar que trajo consigo el surgimiento de los trapiches paneleros y posteriormente de los ingenios azucareros a comienzos del Siglo XX, y que hoy constituyen un emporio económico representativo en el sur del Valle del Cauca y Norte del Cauca.

\subsection{Resultados del estudio de campo: presentación y análisis}

Es interesante notar cómo se reflejan estas particularidades de los afrodescendientes en las empresas industriales capitalistas, en que la cotidianidad de las organizaciones empresariales son escenarios de caos, donde el pensamiento moderno unificador se manifiesta de diversas formas, como la estructura organizacional vertical, que representa claramente la división entre los que piensan y los que ejecutan las tareas. Como particularidad se evidencia que los directivos de alta y media jerarquía provienen de otras ciudades de Colombia, especialmente de las grandes urbes como Bogotá y Cali, que de alguna manera refuerzan su dinámica laboral alrededor de la lógica de la modernidad capitalista. Su formación académica cuenta con estudios de pregrado y posgrado en universidades formales de corte occidental, en temáticas relacionadas con el área que dirigen, participación informal en cursos, diplomados y seminarios, y experiencia relacionada con el cargo que ejercen.

En contraste, algunos de los operarios no han terminado el bachillerato, y la formación que han recibido, sobre todo en áreas específicas como troquelado, se deriva de la orientación que reciben de las personas de mayor experiencia en el proceso productivo en las empresas. Esta idea se origina en el pensamiento moderno, donde unos pocos fungen como cerebro pensante y dictador de directrices y otros la mayoría - obedecen; no se limita a aspectos meramente laborales dedicados al hacer, sino que se trata de reticular en otros aspectos de la vida del trabajador. Su perspectiva es diferente, el significado del trabajo cambia en la medida en que sus actividades dentro de la empresa industrial se imponen de manera unilateral; se definen formas de disfrutar el tiempo, rutinas de trabajo, priorización de necesidades a satisfacer 
individual y familiarmente, formas de celebración y festejos particulares, cumplimiento de disciplinas impuestas, entre otros.

Ahora bien, esa lógica moderna capitalista, que define el manejo de espacios y de tiempo comunes entre los integrantes de una organización industrial manufacturera como Gráficos S.A, impide el reconocimiento de otras lógicas y percepciones de los habitantes y trabajadores de una región con expresiones culturales y étnicas diversas como el Norte del Cauca, que de una u otra forma, afectan el funcionamiento prescriptivo de las organizaciones empresariales.

Para ilustrar estas diferentes lógicas, en los inicios de operación de la empresa, algunos operarios no iban a trabajar pero enviaban de reemplazo a un pariente cercano para que los sustituyera en el trabajo y de esta forma cumplir con el compromiso laboral. Esta actitud tiene su explicación en las raíces de la labor agrícola, ya que era normal enviar reemplazos en actividades relacionadas con la siembra y cosecha; en cambio, en la industria se requieren habilidades básicas con los instrumentos de trabajo, y este cambio de una actividad agrícola a una industrial se ve reflejado en el comentario de un operario de troquelado del área de producción: "yo es primera vez que trabajo en empresa porque me daba miedo quedar mal" (E9, P1). El temor que expresa el operario se debe a que en la empresa se requiere un conocimiento puntual, manejo de tecnología y de múltiples variables adicionales que demandan tiempo para aprender. Además, valoraciones de falta de compromiso son comunes en la percepción de los gerentes, que incluso juzgan que los operarios no logran seguir reglas básicas de una rutina laboral:

Hay gente que no ha dado la talla en la organización, esto es muy complicado a pesar de que no son procesos que demanden mucha exigencia, es gente que no ha sido posible que se adapte al estilo de trabajo de la empresa, que no es nada del otro mundo: son simples hábitos laborales, respeto por los horarios, respeto a la autoridad, respeto a los compañeros y cumplir con las actividades, sin embargo hay gente que no cumple (E4, P17).

A partir de esta introducción, se puede mencionar que la primera macrocategoría que presenta el modelo de análisis del discurso de Greimas (1976) es la manipulación (externa e interna), de ahí proviene en gran parte las ideas de los actores. Es preciso identificar ¿quién hace creer? o ¿quién hace hacer dentro de la empresa? Estos interrogantes están ligados a buscar, en orden de relevancia, quién lo ejerce y qué hace creer o hacer, qué mecanismos utiliza y qué devela la opacidad del discurso, es decir, lo que los actores tratan de negar con las acciones que impulsan.

En este caso, las otras empresas hacen creer a los directivos de Gráficos S.A que existen unos hábitos laborales que son comunes y por lo tanto se actúa en forma coherente con esa creencia, desconociendo el contexto cultural de la región. Asimismo, como un intento de acercamiento entre las dos realidades, de acuerdo al diálogo con los operarios de la planta de producción, es común ver al gerente en la planta hablando con las personas, preguntando por la familia y por los recientes resultados en los partidos de fútbol del torneo nacional, o jugando fútbol los viernes por la tarde con las personas que comparten esa afición, independiente del cargo que desempeñan en la empresa; esto le permite entablar un diálogo y acercamiento con ellas y a la vez demarcar espacios para ejercer su rol de gerente.

Entre los mandos medios, el gerente influencia a creer en el crecimiento de las personas junto con los rendimientos de la empresa, para que a su vez eso sea transmitido a los subordinados, por eso de forma repetida se escucha entre dirigentes y dirigidos: "si la empresa crece todos crecemos" (E1, P17), frase acunada por el gerente general. Explícitamente lo manifiesta la psicóloga: "nosotros estamos muy regidos por la gerencia" (E3, P15), "el gerente nos dice: debes darle a la persona el valor que se merece, haga que los demás crean en él, que los demás vean la persona que es" (E3, P26).

En su orden, el director del área de producción es la persona que manipula en la organización en el creer y hacer en función de la eficacia, su formación en el área de la ingeniería se ve reflejada en su afán por medir resultados, tener todo bajo control en la empresa y exigir la disciplina en cumplimiento de horarios y objetivos, esta forma de ver el trabajo en la empresa lo hace creer y materializar a las demás personas, así lo expresa en la entrevista: "se les dice: aquí hay que rendir cuentas y aquí no venimos a dañar trabajos" (E1, P23). "se les dice: aquí hay que rendir cuentas y aquí no venimos a dañar trabajos" (E1, P23); y también "El tema es meter a todos en el cuento, porque hay personas que están desenchufadas de a dónde queremos ir. [...]" (E1, P24).

En el análisis del individuo virtualizado ${ }^{5}$, la segunda categoría del modelo de Greimas (1976), se puede abstraer del corpus una controversia por el querer hacer y ser, respecto de la cultura diferenciada que han detectado los actores organizacionales. En el corpus de los discursos de Gráficos, se identifican dos 
tendencias por parte de los actores: por un lado, un enfoque hacia mejorar la eficiencia en la producción, que involucra querer crear mecanismos para conquistar la confianza en la planta de producción y evitar de esta forma los retrocesos, consecuencia de los errores y descuidos de las personas; por otro, se quiere crear una cultura de la eficiencia por parte de los dirigentes representados en los mandos medios, que involucra a su vez querer que la gente esté motivada en pro de esa eficiencia. En esta motivación de querer hacer o crear mecanismos para mejorar la eficiencia, se identifica una diferenciación entre grupos dentro de la organización, el nosotros y ellos, expresando un contraste entre el rendimiento de los operarios y los dirigentes en términos de productividad.

de hecho, con la gente de calidad, he intentado establecer un mecanismo en que la gente sea y entienda que nuestro enemigo es la confianza, ha sucedido que en los procesos generales son los mismos y están imprimiendo el mismo trabajo días enteros y por confianza me distraigo y puedo hablar un rato con mi compañero, pero en este tipo de proceso que cualquier variable falle daña la producción, hay que crear esa cultura de que no te puedes confiar, debes estar constantemente verificando porque al menor descuido significa tirarse un trabajo, en la empresa estamos hablando de un trabajo de mínimo de 2 millones y máximo 20 millones de pesos (E1, P8).

Se determinan, entonces, dos grupos: la cultura de ellos, los identificados como individuos de la región, que además coinciden con los cargos de operarios y auxiliares, y la de nosotros, los que tienen cargos de mayor autoridad, tienen experiencia laboral en otras organizaciones y además no son de la región. Esta diferenciación se puede recrear también en el escenario de las celebraciones, como lo describe la psicóloga organizacional:

Hay una forma de celebrar muy particular que es en espacios cerrados, solo Gráficos S.A hemos tratado de incluirnos en la cultura de ellos, en donde domina el trago y la rumba, básicamente esas son nuestras celebraciones. El día del trabajador alquilamos un sitio sólo para nosotros, donde vamos y almorzamos compartimos un ratico y de ahí tienen su baile, su trago. Al gerente también le gusta, entonces él lleva su parrandón y así es como siempre celebramos. Cuando es el día de las madres o día de la mujer, ya algo más mío, un almuerzo, un chocolate, una carta, pues porque no es para toda la organización (E3, P15).

En el análisis de lo que se hace y lo que no se hace, la tercera categoría de análisis, hay relatos que se destacan. En el primer momento, lo que es visible es lo que la Fundación efectivamente realiza. La concepción de desarrollo de la región es entendida desde la perspectiva de eficiencia y de eficacia en los aspectos financieros, sociales, culturales y económicos, aspectos que se deben trabajar en la Fundación para la región de influencia:

Lo que hacemos es, por ejemplo, buscar descuentos con los proveedores que ya tenemos nosotros para que nos sobre la plata y esa plata que nos sobra, volver a invertirla en la misma causa $[\ldots]$ o sea, nosotros hacemos una buena gestión de compras para poderlo reinvertir en los niños, por ejemplo en la primera infancia otra vez, ellos le dan pan y chocolate, nosotros le damos pan, chocolate y una fruta, por decir, nosotros reinvertimos en los niños y así pasa con los otros programas [...] nosotros tratamos es de optimizar los recursos para darle mejor bienestar a la comunidad (E1, P1).

Pero el saber también está representado en la curva de conocimiento en la zona y de experiencia en temas puntuales que se desarrollan en cada una de las secciones que manejan los coordinadores. Esto se refleja en los relatos a continuación:

Lo que estamos haciendo es producto de un ejercicio de años... (E2, P5).

La Fundación lo que dice es hagamos lo que sabemos hacer e impactemos a cinco municipios, por ejemplo (E1, P6).

Ellos pusieron la vaina participativa de la comunidad, o sea que eso forma parte también de los logros que se ha hecho en la región [...] esa es la dinámica de la fundación en todo lo que usted se pueda imaginar (E1, P12). 
Existe además un saber implícito derivado de la relación estrecha entre la gran mayoría de las personas que trabajan en la Fundación y su lugar de origen, de hecho en el equipo conformado por los coordinadores del área y el director, tres personas de cinco son de la región de influencia de la Fundación, lo cual ha permitido comprender las causas y las consecuencias de la problemática social que tiene la zona de la microrregión dos del Norte del Cauca.

El segundo aspecto es sobre las celebraciones de acontecimientos sociales especiales en la empresa, aunque existe un choque de lógicas sobre cómo celebrar, pues no se entiende el sentido de la celebración que tienen los operarios de origen campesino afrodescendiente, en relación a los dirigentes mestizos, procedentes de lugares diferentes a la zona. Esta lógica de celebración dispar se convierte en un criterio de diferencia, recreando la categorización de los grupos en la empresa, ellos, los que festejan alrededor de la fiesta y la rumba, y nosotros, los que festejan de forma más mesurada. Es preciso traer a este contexto que entre las comunidades afrodescendientes, se distinguen tres tiempos complementarios, como lo plantea Albán (2007): el tiempo ordinario relacionado con el tiempo cotidiano de la producción; el tiempo de la celebración, que se constituye en el espacio de distención de la vida cotidiana; y el tiempo de la espiritualidad, donde se mezcla lo sacro y lo profano. La celebración es considerada un tiempo-espacio importante que demanda preparación, tiempo y disposición, por eso lo que para la psicóloga de la empresa es considerado como una forma de celebración (por ejemplo regalar un chocolate el día de la madre), para los afros se hace alrededor de una gran fiesta, con música, comida y licor.

En coherencia a este choque de perspectivas, el corpus da a conocer que para los dirigentes algunos de los obstáculos (cuarta categoría analítica) a la dinámica industrial capitalista, son: la pérdida de tiempo por parte de los operarios dentro de la jornada de trabajo, la indisciplina y la cultura de los operarios considerados como "ellos". El director del área de producción y el coordinador del área de troquelado de Gráficos, lo expresan así:

... eso se ve en todo lado y hay personas muy buenas, rinden mucho pero son indisciplinadas; [...] el trabajador integral es el que cumple con los resultados, es un tema de desempeño. Ahí es donde ellos no entienden que yo quiero que no solo hagan lo de 6 horas, pero tampoco quiero que en dos horas hagan lo de 6 y después hagan perder el tiempo a otro que está por ahí (E1, P24).

Los problemas más que todo es que a veces son como muy tercos y es como lo que más lo sacan a uno, uno también les dice traten de no hablar mucho porque un descuido puede traer muchas consecuencias, puede haber mucha pérdida de material y pueden haber errores que pueden ser incorregibles. Y eso es lo que uno tiene hacer caer en cuenta a las personas, entonces por eso les digo, si tienen algo que hablar vayan al baño y lo hablan y ya vuelven concentrados, y sobre todo con temas de fútbol se la pasan hablando mucho, entonces yo les digo, si quieres vayan y juegan y vuelven $[\ldots]$ ( E6, P5).

En lo que se refiere a la quinta categoría, el estado de realización ${ }^{6}$, los directivos de área o mandos medios expresan su realización por los cambios que han podido hacer en la organización con su aporte; así, el director de producción se refiere a los resultados en el área que dirige: "Llevo dos años con ellos y he logrado cosas positivas con ellos" (E1, P28). Por su parte, el director financiero manifiesta el gusto por el cumplimiento de sus metas: "he tenido tasas de crecimiento de dos dígitos en las ventas y todo esto se ha hecho porque todos trabajamos" (E2, P19); el director de gestión humana reconoce la importancia del perfil de cargos que él ha diseñado, cuando expresa: "bien importante para nosotros es tener nuestro perfil de cargos, ahí está todo lo que se requiere para un cargo" (E4, P8). En cuanto a los operarios o colaboradores, como son llamados en la organización, su grado de realización está en la posibilidad de aprender que han tenido a través de la empresa, ya sea por medio de instituciones educativas o a través de la formación técnica que le han dado dentro de la empresa los líderes de un proceso específico, o en los ascensos logrados:

Yo empecé en la parte de empaque, sin ningún conocimiento sobre esto, la empresa me dio la oportunidad de capacitarme, de hacer unos cursos en el SENA ${ }^{7}$ y de allí me ascendieron a supervisora de calidad. [Las personas que ingresaron a la empresa con algún grado de formación, valoran la experiencia], uno piensa que estudiando uno aprende todo, pero no, la práctica es muy importante, aquí he aprendido muchas cosas (E5, P4). 
Soy tecnóloga en control ambiental del SENA [...] yo empecé haciendo aseo en las oficinas, vieron mis capacidades y me dieron la oportunidad de trabajar en la división ambiental (E5, P5).

En el corpus se identifican aspectos en los que los individuos se consideran en un estado de no realización: la inconformidad con el rigor del ritmo y reglas de trabajo, con las condiciones ambientales de la empresa, con los resultados de la gestión humana y con la poca atención a las expresiones culturales. Los discursos revelan que los directivos de área expresan de forma unánime la no realización frente a los hábitos laborales de las personas, esto es, las prácticas de los colaboradores de faltar en forma recurrente y generalizada a trabajar los días lunes, el incumplimiento del horario de trabajo, principalmente en los turnos adicionales en épocas de alta producción, la presentación justificada en el área de gestión humana de la excusa de inasistencia al puesto de trabajo. En coherencia con este aspecto, los colaboradores manifiestan la no realización con las jornadas extendidas de trabajo, pues "muchas personas se la pasan mucho tiempo en el trabajo y tal vez descuidan un poco la vida familiar que es muy importante, a veces compañeros me han comentado que no han podido ver a sus hijos por los horarios de trabajo, eso pasa principalmente cuando hay mucha producción" (E5, P15).

El entendimiento del tiempo de una forma ecléctica por parte de las comunidades campesinas afrodescendientes, permite conjugar actividades laborales paralelas al relacionamiento social, todo lo cual está vinculado directamente con la oralidad que hace posible la construcción del mundo de la vida. Así, el desarrollo de valores como la solidaridad y el trabajo en comunidad, se manifiestan en el espacio del trabajo en la empresa industrial cuando el trabajador termina la labor encomendada y se dedica a dialogar con sus compañeros, o cuando como un gesto de solidaridad el hermano va a reemplazar al otro en su jornada laboral, este comportamiento contraviene el disciplinamiento industrial de la lógica moderna, en la que en el espacio de la jornada de trabajo el individuo no puede realizar ninguna otra actividad que no esté enmarcada en la producción, y no se admiten valores diferentes a la eficiencia y la eficacia productiva.

Finalmente, en relación a las valoraciones, la última categoría de análisis, los discursos reiteran el comportamiento necesario en una empresa industrial que representa una lógica moderna capitalista y choca de forma directa con una lógica de producción campesina-afrodescendiente, en la que el manejo del espacio y el tiempo están lejos de ser rígidos y estandarizados, y se acerca al relacionamiento social que surge mientras se trabaja. Características como la solidaridad, el diálogo permanente, la celebración con el otro, la destinación del tiempo a otras esferas de la vida diferentes al trabajo, son importantes para los trabajadores de la región y por tanto también requieren atención por parte de los dirigentes. Desde esta perspectiva, se entienden muchas de las acciones que valoran negativamente los dirigentes, especialmente de la empresa Gráficos S.A., como: termina su trabajo y desplaza hasta el puesto del compañero a ver qué actividad realiza, o hablar todo el tiempo con su compañero mientras opera la máquina a su cargo, incluso es normal que el día que no va a trabajar un operario envía a su hermano a reemplazarlo en la empresa.

La valoración positiva del trabajo que se desarrolla en la Fundación, se complementa con la buena medición del clima y la cultura organizacional, entre otros indicadores:

Nos fue muy bien en la encuesta de clima organizacional, nos fue verde en visión estratégica $100 \%$, en temas de clima y en temas de liderazgo $100 \%$ (E3, P32).

La movilidad dentro de las Fundación es mínima, las personas que se van es porque se les presentó una oportunidad mejor en otro lado, pero la rotación es mínima, entonces digamos eso habla muy bien de la empresa (E2, P9).

En el corpus se identifican tres hallazgos puntuales que son valorados negativamente en la Fundación: la gestión de dirección anterior de la Fundación, el enfoque de asistencialismo que propiciaba la Fundación y las condiciones sociales y económicas de la zona y abandono del estado en la región.

\subsection{Buscando una síntesis}

La visión de ambas organizaciones es contraria en cuanto a la forma de intervención social y productiva que realizan. Vemos primero a Gráficos S.A. como una empresa industrial que se crea en el norte del departamento del Cauca, como resultado de la estrategia de diversificación de una multinacional farmacéutica. La iniciativa de crear Gráficos S.A. se dio con el objetivo de facilitar la adquisición de empaques de buena calidad y de fácil surtimiento para los medicamentos que esta industria farmacéutica 
producía. Claro que Gráficos S.A. tiene una clara influencia de la empresa principal, Gráficas Nacional S.A., que opera en Bogotá. De hecho, algunos de los trabajadores de Gráficos S.A., entre los que se cuenta el gerente general y el coordinador del proceso de troquelado y el coordinador de impresión, junto con tres personas más, pertenecieron a la empresa matriz y se encargaron de difundir las mismas prácticas en la nueva empresa. Esto supone condiciones del entorno iguales en Bogotá y en Guachené, donde actualmente está asentada la empresa, lo que ha ocasionado una serie de inconvenientes para los dirigentes organizacionales.

La intervención de la empresa, por tanto, se da unilateralmente, y se ve el incentivo para su creación en esta zona como meramente económico, por estar cobijada por la Ley 218 de 1995 y posteriormente por ser zona franca. Sin embargo, no existen consideraciones de reconocimiento social y cultural desde la dirección y administración de la empresa matriz. El hecho de que todas las personas que ejercen cargos de dirección de mandos medios y altos no sean de la región y que no vivan en la región de influencia de la empresa, es significativo de la desconexión que existe entre los hábitos y prácticas culturales del entorno de los operarios. Es interesante notar que la empresa ha buscado una estrategia de dominación para poder controlar esta diferencia de lógicas.

Por su parte, el director de gestión humana es quien mayor injerencia tiene en la institucionalización de los hábitos laborales, tales como el cumplimiento de horarios, acato a la autoridad, respeto a los compañeros y dedicación a la labor que se le asigna. Se ha implementado la estrategia de seguimiento a las visitas domiciliarias, que han dado la información para tomar acciones conducentes a influenciar en los trabajadores a tener una expectativa de vida diferente, como el caso de conferencias acerca del manejo de las finanzas familiares, adecuación o construcción de viviendas, etc.

Otra estrategia utilizada es la vinculación de la familia del trabajador a la empresa, a través de jornadas de visita de los hijos de los operarios en horas de trabajo para que ellos conozcan lo que hacen y se convierta en un motivo más de estímulo para rendir en el trabajo. Estas acciones implementadas hacen creer al operario la importancia que tiene para su familia y lo importante también del mejoramiento en las condiciones de vida de las personas que la integran, convirtiéndose en una estrategia de manipulación interna. En el corpus: "El hijo de un trabajador de hace años en la empresa lo vio trabajando y lo primero que dijo es: ese es mi papá, él es el que mueve esa maquinota, mi papá es un duro. Él escuchó eso y para él es inolvidable eso" (E1, P19).

La Fundación Cauca, por su parte, tiene un enfoque que contrasta con el de Gráficos S.A., pues la Fundación Cauca está pensada para canalizar las necesidades de la comunidad de tres municipios: Guachené, Villa Rica y Puerto Tejada. Y su intervención es de afuera para adentro; es decir, conoce, explora, acompaña y finalmente propone los servicios que puede ofertar hacia las comunidades locales. Los mandos medios, en su gran mayoría oriundos de la región, no solo conocen la problemática social, sino que sienten como propio el trabajo con la comunidad.

El director como autoridad formal traza un estilo de dirección, derivada del cargo que desempeña en la organización, el cual se ve reflejado en la priorización de servicios que presta la Fundación y por ende en la concentración del esfuerzo de los funcionarios y los recursos en servicios como la atención a los niños de primera infancia, programa que surgió por iniciativa del director y el trabajo en la prevención de salud; el reforzamiento de elementos como la comunicación intergrupal; el empoderamiento entre los trabajadores; el contacto cercano de los coordinadores de área con la empresa y la rendición de resultados periódicamente: "procuro ser muy señor, exigente, serio y también ser amable. [...] creo que tengo una buena relación con la gente, siento confianza en la gente, empodero mucho, dejo trabajar, pero pido la tarea" (E5, P24).

Tal vez, este rasgo diferenciador proviene de muchas variables como la esencia social del ser humano, la asistencia social, el reconocimiento de la comunidad a las personas que pertenecen a la Fundación Cauca, entre otras. Tal como se evidencia en los datos recolectados, la afinidad y pertenencia con el territorio hace sin lugar a dudas la diferencia de valor con otras organizaciones.

Sin embargo, aunque los integrantes de la Fundación hacen una crítica de las empresas enfocadas hacia objetivos unidireccionales de carácter económico y exaltan el valor de los rasgos culturales propios de los afrodescendientes de la región, no hay una manifestación expresa del respeto por la forma en la que esta comunidad percibe la vida en su territorio, que involucra sus actividades económicas de forma independiente ligadas al trabajo de la tierra, el manejo del espacio y del tiempo de acuerdo a las condiciones socioambientales y del ciclo de productividad de la tierra, entre otras muchas características.

Como se puede observar, el discurso es coherente con las necesidades de la industria asentada en la región (Cartón), en términos de talento humano dispuesto, capacitado en determinadas funciones y con actitud hacia el trabajo que va de acuerdo a las nuevas dinámicas económicas regionales. De cierta forma lo 
que está haciendo la Fundación podría ser preparando la base social para incorporar a los individuos a la lógica moderna- capitalista que no estaba masificada y desarrollada en la mente de la gente de la región, principalmente de los afrodescendientes.

En la lógica capitalista de la empresa industrial, existe una verdad meramente racional frente a la acumulación de capital como objetivo primordial que justifica la creación de la empresa, que es adoptado e interiorizado por los dirigentes organizacionales. Por otro lado, éstos son los encargados de adoctrinar a los operarios y auxiliares de la organización, quienes como regla general no han tenido experiencia laboral en empresas industriales ni una formación académica que direccione hacia esta lógica, de allí que para ellos el trabajo sea una arista de su vida.

La diferencia, en el contexto de las organizaciones estudiadas, se convierte en una tecnología que ayuda a referenciar a unos grupos de otros, desde los cuales es posible destacar ciertos aspectos en los que el individuo se cree superior o en mejor condición. También sirve para homogenizar a todos los individuos cuando las condiciones son impuestas por un contexto específico; por ejemplo, a todos los individuos que venden su capacidad de trabajo a la empresa se les exige eficiencia, independientemente del cargo que ocupen, pero dentro del mismo grupo de individuos que venden su capacidad de trabajo, se establecen diferencias para destacar a un grupo al que se pertenece, sobre otro que se cree de menor categoría.

Así, el criterio de diferenciación que se utiliza para distinguir un grupo de individuos de otros, se convierte en el principal motivo de categorización entre el endogrupo, los que comparten rasgos comunes, y el exogrupo, es decir los que se alejan a estos rasgos. Es necesario enfatizar que entre más cercano esté el trabajador a un grupo social diferente al suyo, más aferrado es el discurso. Caso concreto se observa en los dirigentes o mando medios, que si bien pertenecen al grupo de los trabajadores de la empresa endogrupo - , son los que más interiorizado tienen el discurso de la maximización de utilidades, perteneciente a los accionistas - exogrupo.

Pero no sólo la racionalidad económica es la que permite la alteración de las actitudes de los individuos, también la institucionalización de la cultura productiva aprendida en la experiencia laboral en otras empresas o por la formación profesional bajo la lógica de programas académicos con un marcado énfasis en el mercado.

Hay una relación entre la influencia que se deriva de la educación formal en las ciencias de la administración y demás relacionadas, que tienen un fuerte componente de conocimiento Norteamericano o Europeo, y lo que se quiere implementar en las organizaciones locales, lo cual trae como consecuencia el blanqueamiento de las condiciones sociales y económicas propias, propiciando un círculo de reproducción de conocimiento hecho para otros contextos, de ahí que se obtengan resultados distorsionados de los ideales que se esperan conseguir en cuanto al impacto social, económico y cultural de los contextos donde operan.

A través del análisis de discurso que se hizo, en Gráficos S.A. y Fundación Cauca se puede apreciar el rol de las organizaciones como un centro de aprendizaje (positivo o no) para las personas que lo integran, que pueden cambiar en el largo plazo las dinámicas regionales en los diferentes aspectos del individuo, ocasionando una especie de mutación entre lo que se es y lo que se quiere imponer en el individuo; por ejemplo, las personas de la región aprendieron a ahorrar, a invertir su salario, situación que resalta el impacto que tienen las empresas en el entorno.

Las valoraciones éticas, estéticas y pasionales de los dirigentes y dirigidos de la Fundación Cauca dan muestra de la configuración del hombre como ser social, dado que existe una nutrida valoración positiva relacionada con el trabajo que realiza y sus efectos en la comunidad en la que opera la Fundación Cauca. Estas valoraciones conllevan a plantear que la organización quiere proporcionar al individuo el espacio para realizarse, no solo profesionalmente sino también personalmente; es decir, debe ser el espacio de interacción social propicio para que el individuo se interrelacione con otros y sea además co-creador con el otro, trabajando en la organización en un entorno de comprensión social, política, económica del hombre, frente a la sociedad a la que pertenece.

En ese sentido, el trabajo de la Fundación Cauca como organización social sin ánimo de lucro debería reafirmar las características y expresiones culturales de la población afro descendiente que por mayoría está en la región, pues hasta ahora se hacen actividades o eventos esporádicos que se realizan con recursos de entidades públicas y por el contrario la mayor parte del presupuesto de la Fundación está sustentado en los servicios que pueden ser valorados por la empresa de la cual provienen sus recursos financieros.

Sin embargo, concomitante a este planteamiento, a través del análisis de discurso se manifiesta que existe un pensamiento arraigado sobre la función económica de la organización, que no es novedad en 
nuestro contexto si se liga el argumento planteado en este trabajo, de la diferencia como elemento de fondo para privilegiar los intereses en favor de los accionistas en detrimento de los intereses de los trabajadores.

Uno de los rasgos heredados de ese momento histórico de la colonización, que constituye la justificación más fuerte para analizar el choque de culturas en este estudio, es la negación por lo propio, esto es, por la forma de ser como sujetos y de vivir en el contexto. El trabajo de campo da cuenta de cómo la lógica capitalista, incrustada en los dirigentes industriales, desconoce las características sociales, políticas, económicas y hasta geográficas de la región donde llegó a operar. En el caso particular de Gráficos S.A., se impone una nueva lógica foránea a los pobladores propios de la región, dándose lo que Bolívar Echeverría plantea como mestizaje cultural. Ésta ya no es comprendida desde la motivación de sobrevivir al aniquilamiento biológico al que estaban expuestos los indígenas de la época, sino desde la sobrevivencia socio-cultural que implica la imposición de nuevas dinámicas y de grupos distintos de pertenencia.

Respecto al análisis de los rasgos de tabú, puntualmente alrededor de la relación entre el máximo jerarca de las organizaciones y los demás miembros de las mismas, se puede rescatar que la fuerte imagen de poder proviene de diversas fuentes de autoridad.

En el corpus se manifiesta el reconocimiento del poder por parte de los actores organizacionales de mayor jerarquía sobre los de menor jerarquía, que tienen su fuente en la relación gerente-mandos medios, y se replica de los mandos medios hacia sus subalternos. Ese reconocimiento se expresa en la forma como se dirigen a sus jefes ("A mí me dicen ingeniero [...]cuando a mi alguien me llama por mi nombre yo siempre le digo -hijo, así me llaman en la casa [... ] eso sí crea una marca de respeto" - E2, P25).

La empresa ha tratado de suprimir las denominaciones tradicionales que tienen un contenido social dentro y fuera de la empresa. Se ha hecho un esfuerzo para suprimir el término "doctor", muy común en el contexto colombiano para exaltar la importancia social que puede tener una persona, y se ha reemplazado por el término "Don". En el caso de los trabajadores, se les ha denominado colaborador, en un afán por el reconocimiento a la labor que realizan en la empresa.

Entre las que se puede distinguir están: la autoridad derivada del cargo formal que tienen en la empresa, sustentado en el poder de decisión que tienen sobre cada persona contratada en la organización; la autoridad que proviene de la experiencia y el conocimiento de cada proceso que allí se realiza, ya sea por experiencia como el caso del ascenso paulatino del gerente de Gráficos S.A. que ejerció desde operador hasta gerente, o desde el conocimiento formal, como el caso del gerente de la Fundación; se reconoce también una autoridad carismática propia de la personalidad y cercanía con los que los rodean, que contrasta con el carácter y temple en el momento de tomar decisiones radicales en la organización; la autoridad emanada de la gestión del cambio que han promovido dentro de las organizaciones para que muden, ya sea en el enfoque de trabajo o en el crecimiento de las mismas, junto con la incidencia que han tenido para cada individuo que integra la organización directa o indirectamente. Paralelamente, el manejo de elementos físicos y de acceso al gerente, ayuda a afianzar el tabú de los dirigentes organizacionales. Aspectos como la infraestructura física de las oficinas que ocupan, la antesala necesaria para acceder al gerente y los accesorios como pinturas, muebles especiales y demás, acentúan la diferencia entre el gerente y los demás miembros de la organización.

\section{CONSIDERACIONES FINALES}

El objetivo de esta investigación fue construir una comprensión sobre como la diferencia es tratada en la gestión. Se planteó como lentes de análisis la perspectiva psicosocial, sociológica e histórica, con una discusión construida desde el pensamiento latinoamericano.

En la discusión de los resultados, llamó la atención la dinámica de los encuentros y las tensiones entre la lógica empresarial basada en la racionalidad instrumental y la lógica barroca presente en la dinámica social en el grupo de los trabajadores. A partir de una rápida lectura de las dos organizaciones estudiadas, podría dar la impresión de que son totalmente diferentes en cuanto a los objetivos que persiguen: la empresa industrial trabaja para maximizar la utilidad de los accionistas y la Fundación Cauca, trabaja para el desarrollo social de la comunidad a la que esta direccionada. Sin embargo, aunque sus labores son distintas, en el análisis del discurso se devela un interés de la organización con ánimo social (Fundación Cauca) de trabajar para el cumplimiento de los objetivos empresariales, puesto que los programas sociales que emprenden si bien llegan a la comunidad con servicios que son requeridos, no se distancian del interés empresarial.

Es claro que la empresa no puede subsistir en un ambiente social y económico deteriorado, requiere de condiciones mínimas para poder desarrollar su actividad económica. Así, la capacitación del personal, el 
acompañamiento psicosocial para el direccionamiento de la población en edad de trabajar, el aprovisionamiento de los servicios públicos y de salud, la creación de empresas que prestan servicios complementarios a las empresas industriales, son apenas necesarias para el normal desarrollo de la empresa en la región, que asegura el funcionamiento de la misma en el largo plazo y de esta forma garantiza el mayor rendimiento del capital invertido.

Dentro del análisis del contraste de la organización como un sistema abierto, en el que es necesario adaptarse a las condiciones del entorno y la valoración de la lógica moderna capitalista, se evidencia una contradicción, puesto que la empresa, como institución, no permite la permeabilidad de otras lógicas diferentes y de otra clase de valoraciones que no sean: la eficiencia y la eficacia. Gráficos S.A. y la Fundación Cauca, asentadas en un territorio de mayoría afrodescendiente, niegan a través de los actores internos dirigentes, las manifestaciones culturales y lógicas campesinas en forma de criterios de diferencia, a partir de los cuales los trabajadores sería considerados de menor dignidad y por tanto se hace necesario trabajar para desaparecer, dando vida a la concepción de blanquitud, planteado por Bolívar Echeverría (2010).

Teniendo en cuenta lo anterior, en el corpus se evidenció un choque de la dinámica cultural y de disciplina que impone la lógica moderna capitalista, en contraposición a la lógica campesina afrodescendiente. Gráficos S.A niega el contexto en el que opera, aplicando unos patrones construidos en otro lugar para ser implementados en contextos diferentes, sin tener en cuenta la trayectoria histórica-cultural que pueden tener, en este caso puntual, los trabajadores afrodescendientes campesinos; así, se plantea una lógica no solo productiva, sino una forma diferente de vida en los individuos a partir de la dimensión creada por la lógica colonial.

Por su parte, la lógica campesina afrodescendiente se desarrolla con un manejo del espacio y del tiempo diferenciado de la dinámica moderna capitalista. En coherencia a este choque de perspectivas, por parte de los dirigentes se identifican como obstáculos a la dinámica industrial capitalista: la pérdida de tiempo por parte de los operarios dentro de la jornada de trabajo, la indisciplina y la cultura de los operarios considerados como "ellos".

La lógica moderna capitalista que está institucionalizada en los dirigentes organizacionales y validada por los demás miembros de la organización, da fuerza a la condición humana representada en el rol del trabajador como lo único que se valora en el sistema en el que está inmersa la empresa. De esta forma, no sólo los afrodescendientes, sino todas las personas reunidas en torno a la organización, son vistas como seres humanos que interpretan el rol de trabajador y que por tanto son recortados en su calidad de individuos, en su ser social, en su ser económico y en su expresión de la tradición histórico cultural que configura su existencia, para quedarse en la dimensión laboral productiva.

Sin embargo, a de considerase que la dinámica cultural se constituye como un espacio en el que los individuos manifiestan su espontaneidad y se torna lo que Albán (2008) llama de práctica de-constructiva capaz de de-colonizar nuestras mentes. Es importante entender que la de-colonialidad es definida por el autor como un proceso de reconocimiento de historias, trayectorias y cosmovisiones que muchas veces dista de la llamada racionalidad moderna del sistema capitalista.

Un aprendizaje significativo de todo esto reside también en el aporte de la metodología, en la que se valoran perspectivas que no son tomadas en cuenta en la praxis del análisis organizacional. A partir de ello, fue observado cómo las construcciones históricas, psicosociales y sociológicas ejercen influencia importante en la dinámica social.

En fin, como un último aprendizaje de este estudio cualitativo, se afirma que podemos comprender las diferencias como más accesibles a través del análisis del discurso y, en consecuencia, desde la óptica de deconstrucción, se puede reformularlos e re-interpretarlos. Las perspectivas garantizan, a nuestro ver, que la investigación cualitativa está en permanente construcción y, en el caso de este artículo, una contribución adicional a la discusión está en usar autores del pensamiento latinoamericano para levantar otras posibilidades - otras miradas para entender la realidad de la gestión en las organizaciones.

\section{REFERENCIAS}

Aktouf, O. (2003). La administración de la excelencia: de la deificación del dirigente a la cosificación del empleado. In: Rafael Carvajal de Baesa (edit.), El Lado Inhumano de las Organizaciones. Cali: Universidad del Valle. 
Albán, A. A. (2007). El acto creador como pedagogía emancipatoria y decolonial. Ponencia-performance presentada en el 5 Seminario de Formación Artística: encuentro con la creatividad, el arte y la educación, organizado por la Institución Educativa La Pamba, Popayán, Colombia, 10 al 12 de octubre.

Albán, A. A. (2008). Artistas indígenas y afrocolombianos: entre las memorias y cosmovisiones. Estéticas de la Re-Existencia. Ponencia presentada en el Seminario Internacional "Arte actual de los pueblos originarios", organizado por el Convenio Andrés Bello, pág. 83-116. Quito, Ecuador.

Arendt, Hannah (1996). La condición humana. Barcelona: Paidós.

Bastide, R. \& Van Den Berghe, P. (1957). Stereotypes, norms, and interracial behavior in São Paulo, Brasil. American Sociological Review, 22 (6), 689-694.

Bastide, Roger (1967). Las Américas negras: Las civilizaciones africanas en el Nuevo Mundo. Madrid: Alianza Editorial.

Brewer, M. \& Weber, J. (1994). Self-Evaluation effects of interpersonal versus intergroup social comparison. Journal of Personality and Social Psychology, 66 (2), 268-275.

Calderón, F.; Hopenhayn, M. \& Ottone, E. (1996). Esa esquiva modernidad: Desarrollo, ciudad y cultura en América Latina y el Caribe. Caracas, Nueva Sociedad.

Castellanos, J. (1980). La Abolición de la esclavitud en Popayán. Cali: Universidad del Valle.

Castiglioni, A. (1972). Encantamiento y Magia. México: Fondo de Cultura Económica.

CEPAL (2009). Departamento de Valle del Cauca, Colombia, Perfil sociodemográfico básico. Colombia, CEPAL.

Cruz Kronfly, F. (2003). La presencia de lo inhumano en la cultura y en las organizaciones. In: R. Carvajal Baeza (edit.). El lado inhumano en las organizaciones. Cali: Universidad del Valle.

Echeverría, B. (2008). El ethos barroco y los indios. Revista de Filosofía Sophia, 2, 1-11.

Echeverría, B. (2010). Modernidad y blanquitud. México: Era.

Ellemers, N. ; Kortekass, P. \& Ouwerker J. (1999). Self-categorization, commitment to the group self-esteem as related but distinct aspects identity. European Journal of Social Psychology 29 (2/3), 371-389.

Elliot, G.; Ziegler, H. L.; Altman, B. \& Scott, D. (1982). Understanding stigma: dimensions of deviance and coping. Journal of Deviant Behavior, 3(3), 275-300.

Frazer, J. G. (1969). La rama dorada: magia y religión. México, Fondo de Cultura Económica.

Freud, Sigmund (1917). El tabú de la virginidad. In: Sigmund Freud. Obras completas, Volumen 11. Buenos Aires: Amorrortu.

Freud, Sigmund (1982). Tótem y Tabú. Madrid: Alianza Editorial S.A.

Greimas, A. J. (1973) Semântica estrutural. São Paulo: Cultrix/Edusp

Greimas, A. J. (1976). Semiótica do discurso científico + da modalidade. São Paulo: Difel Difusão.

Ibarra-Colado, E. (2003). Notas para el estudio de las organizaciones en América Latina a partir de la reflexión crítica de la teoría de la organización. México: UAM-Iztapalapa.

Ignatieff, M. (1998). El Honor del Guerrero. Madrid: Punto de Lectura.

Jay, Timothy (2009). The utility and ubiquity of taboo. Sources Perspectives on Psychological Science, 4(2), 153-161.

Kurzban, R. \& Laery, M. (2001). Evolutionary origins of stigmatization: the functions of social exclusion. Psychological Bulletin, 2, 187-208.

Locke, L., Spirduso, W. W. y Silverman, S. (1987). Propuestas que funcionan: una guía para la planificación de disertaciones y grandes propuestas. In: J. Creswell (edit.). Diseño de investigación: Aproximaciones cualitativas y cuantitativas. UK: Sage Publ. 
Discursos sobre la diferencia: lo moderno y lo barroco em la gestión de organizaciones colombianas en la región de Cauca

Miles, M. \& Huberman, M. (1984). Análisis de datos cualitativos: un manual de métodos nuevos. Berverly Hills: Sage.

Mosquera, C.; Pardo, M. \& Hoffmann, O. (2002). Afrodescendientes en las Américas: trayectorias sociales e identitarias a 150 años de la abolición de la esclavitud en Colombia. Bogotá: UN-ICANH-IRD-ILSA.

Quijano, A. (2000). Colonialidad del poder, eurocentrismo y América Latina. In: E. Lander (edit.). La colonialidad del saber: eurocentrismo y ciencias sociales, perspectivas latinoamericanas: 201-242. Buenos Aires: CLACSO.

Rojas, A. (2004). Subalternos entre subalternos: presencia e invisibilidad de la población negra en los imaginarios teóricos y sociales. In: E. Restrepo \& A. Rojas (edit.), Conflicto e (in) visibilidad. Retos de los estudios de la gente negra en Colombia: 157-172. Popayán: Universidad del Cauca.

Scandroglio, B.; López Martínez, J. \& San José Sebastián, M. del C. (2008). La Teoría de la Identidad Social: Una síntesis crítica de sus fundamentos, Evidencias y controversias. Psicothema, 20(1), 80-90.

Spradley, J. (1979) The ethnografic interview. Forth Worth: Hancourt Brace Jovanovich College.

Tajfel, H. (1984).Grupos humanos y categorías sociales: Estudios de Psicología Social. Barcelona: Herder editorial S.A.

Turner, J. (1982). Towards a cognitive redefinition of the social group. In Tajfel, Henri (Ed.) (1982). Social identity and intergroup relations (15-40). Cambridge: Cambridge University Press.

Wade, P. (2004). Negros Indígenas e Identidad Nacional en Colombia. Bogotá: Cuaderno 2 Ahila.

Weber, M. (2006). La ética protestante y el espíritu del capitalismo. Madrid: Alianza Editorial S.A.

Wundt, W. (1907) Outlines of psychology. Leipzig: Wilhelm Engelmann, London, New York.

\section{NOTAS}

${ }^{1}$ La Ley 218 de 1.995 o Ley Páez brindaba excepción de impuestos a las empresas ubicadas en algunos de los municipios afectados por la avalancha del Rio Páez.

${ }^{2}$ La colonización de América Latina tuvo dos ejes de construcción: la colonización española y la colonización portuguesa, con distintos matices, formas y elementos. En este artículo, en función de que nuestro objeto de estudio está situado en Colombia, se va explorar la construcción de la diferencia desde la colonización española.

${ }^{3}$ Traducción libre.

${ }^{4}$ Se entiende por palenques, poblaciones de afrodescendientes fugados de sus amos en la época colonial, a los que se les denominaban cimarrones.

${ }^{5}$ En este primer estado, denominado virtualizado en el modelo de semiótica de Greimas (1976), se establecen cuatro categorías: querer ser/estar, deber ser/estar, querer hacer y deber hacer. El querer aquí deja ver la autonomía de los individuos respecto a algo que quiere ser/estar o hacer. Y el deber representa lo impuesto por el sistema o la institución que representa, esto es, lo que debe ser/estar y lo que quiere hacer.

${ }^{6}$ El estado de realización de los individuos se puede subdividir en dos partes: el estado realizado y el estado no realizado. El primero hace referencia a que el individuo pudo cumplir derivado de su estado virtual, es decir, lo que quiere y debe ser, estar o hacer y en consecuencia el individuo llega a un estado de estabilidad. El segundo estado no realizado, se refiere a que no se cumplió el primer estado virtualizado.

${ }^{7}$ El SENA es el Servicio Nacional de Aprendizaje, institución pública encargada de la enseñanza de programas técnicos y tecnológicos en Colombia.

\section{AGRADECIMIENTO}

Este artículo es un homenaje póstumo a mi querida Nancy Piedad Díaz Ortiz. De alumna, se transformó en una amiga tan entrañable que cuando se fue, se llevó un pedazo de mí. Sin embargo, también me quedé con un pedacito de ella, que vive a través de mí, a través de mis recuerdos y de mi amor. Los lectores podrán recoger el mismo camino de Nancy y mío, en nuestros descubrimientos y sorpresas con las idiosincrasias y similitudes que nos tornan, más allá de las diferencias, seres humanos. 
Data da submissão: 15/05/2017

Data de aceite: 05/07/2017

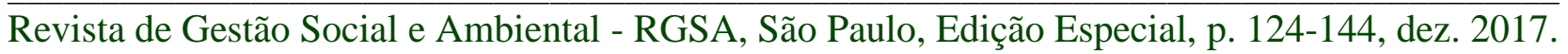

